\title{
Pengembangan Gim Edukasi 2D Pemilahan Sampah Daur Ulang Berbasis Android
}

\author{
Adjie Wahyudinata, Harya Bima Dirgantara
}

Institut Teknologi dan Bisnis Kalbis, Indonesia

\section{Article Info}

Article history:

Received, 1 August 2020

Revised, 4 September 2020

Accepted, 10 September 2020

\section{Kata kunci:}

Android

Gim Edukasi

Pemilahan Sampah Daur Ulang

GDLC

Unity 2D

\begin{abstract}
ABSTRAK
Setiap orang wajib membuang sampah pada tempatnya menurut jenis pewadahannya. Namun berdasarkan hasil survei yang dilakukan oleh Katadata Insight Center (KIC) sebanyak 50,8\% dari 354 responden tidak memilah sampah. Kurang maksimalnya sosialisasi dan edukasi pemilahan sampah menjadi salah satu penyebab masyarakat tidak memilah sampah. Tujuan dari penelitian ini adalah mengembangkan game edukasi aksi 2D tentang pemilahan sampah daur ulang berbasis android yang dapat dijalankan di perangkat tanpa internet. Dengan memainkan gim ini diharapkan dapat menjadi media alternatif untuk sosialisasi dan edukasi pemilahan sampah. Gim ini dibangun menggunakan perangkat lunak mesin gim Unity 2D berbasis Android menggunakan bahasa pemrograman C\#. Metode yang digunakan untuk mengembangkan gim ini adalah metode Game Development Life Cycle (GDLC). Tahapan GDLC terdiri dari 6 tahapan yaitu Inisiasi, Pre-Produksi, Produksi, Testing, Beta, dan Rilis. Hasil akhir dari penelitian ini adalah gim edukasi aksi pemilahan sampah daur ulang berjudul "Kita Pilah Sampah Anda" dengan spesifikasi minimal gawai Android 6.0 marshmallow. Dari total 21 responden masyarakat umum, 76,2\% responden termotivasi untuk memilah sampah daur ulangnya sendiri setelah bermain gim ini.
\end{abstract}

\section{ABSTRACT}

\section{Keywords:}

Android

Educational Game

Sorting Recycled Waste

GDLC

Unity $2 D$
Everyone is obliged to dispose of garbage in its place according to the type of container. However, based on the results of a survey conducted by the Katadata Insight Center, $50.8 \%$ of the 354 respondents did not sort the waste. The lack of socialization and education on waste sorting is one of the reasons people do not sort waste. This research aims to develop a $2 D$ action educational game about sorting recycled waste based on android, which can be run on devices without internet. By playing this game, it is hoped that it can become an alternative media for socialization and education of waste sorting. The game was built using the Android-based Unity 2D game engine software using the $C$ \# programming language. The method used to develop this game is the Game Development Life Cycle (GDLC) method. The GDLC stage consists of 6 stages, namely Initiation, Pre-Production, Production, Testing, Beta, and Release. The final result of this research is an educational action game for sorting recycled waste entitled "We Sort Your Trash" with minimum specifications for Android 6.0 marshmallow devices. From a total of 21 respondents from the general public, $76.2 \%$ of respondents are motivated to sort their own recyclables after playing this game.

This is an open access article under the CC BY-SAlicense.

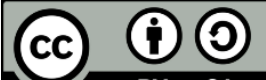

\section{Penulis Korespondensi:}

Harya Bima Dirgantara, Program Studi Informatika, Institut Teknologi dan Bisnis Kalbis. Email: harya.dirgantara@kalbis.ac.id 


\section{PENDAHULUAN}

Dalam pasal 12 Ayat 1 UU No. 18 tahun 2008 mengenai kewajiban pengelolaan sampah, dijelaskan bahwa setiap orang dalam pengelolaan sampah rumah tangga dan sampah sejenis rumah tangga wajib mengurangi dan menangani sampah dengan cara yang berwawasan lingkungan [1]. Namun masih banyak masyarakat yang tidak melakukan pemilahan sampah sendiri. Kurang maksimalnya sosialisasi dan edukasi pemilahan sampah menjadi salah satu penyebab masyarakat tidak memilah sampah. Hal ini dibuktikan dengan hasil survei oleh Katadata Insight Center, yang melakukan survei terhadap 354 responden di Jakarta, Bandung, Semarang, Yogyakarta, dan Surabaya mengenai perilaku pemilahan sampah. Sebanyak 50,8\% responden di lima kota besar Indonesia tidak memilah sampah. Dari 50,8\% rumah tangga yang tidak memilah sampah, 79\% di antaranya beralasan tidak ingin repot [2]. Oleh karena itu, sebuah gim edukasi aksi pemilahan sampah daur ulang berbasis Android dengan menggunakan metode GDLC dibangun, untuk dapat membantu sosialisasi pemilahan sampah dan mengedukasi pemain mengenai pemilahan sampah daur ulang serta apa saja barang yang bisa dibuat dari hasil daur ulang tersebut.

Penelitian sebelumnya oleh Pujastuti et al, membahas tentang pengembangan gim edukasi memilah sampah berdasarkan jenisnya dan memberi rekomendasi daur ulang []ㅡ. Perbedaan penelitian ini dengan penelitian tersebut terletak pada penggunaan metode pengembangan gim. Penelitian ini menggunakan metode GDLC dan penelitian tersebut menggunakan DGBL-ID (Digital Game Based Learning - Instructional Design). Penelitian lain oleh Sudiatmika et al, membahas pengembangan gim edukasi berbasis Android untuk mengenal jenis-jenis sampah yang ada di lingkungan sekitar [4]. Perbedaan penelitian ini dengan penelitian tersebut terletak pada penggunaan mesin gim yang digunakan. Penelitian ini menggunakan Unity 2D dan penelitian tersebut menggunakan Corona SDK. Selain itu penelitian oleh Adiwikarta [5] dan Dirgantara, et al [] menjadi acuan penggunaan metode GDLC untuk membangun sebuah gim, pada kedua penelitian ini dibangun gim dengan genre aksi. Tujuan dari penelitian ini adalah untuk membangun gim edukasi aksi pemilahan sampah daur ulang berbasis Android menggunakan metode GDLC.

\section{METODE PENELITIAN}

\subsection{Gim Edukasi}

Menurut Noemi dan Maximo [7], gim edukasi adalah video gim atau aplikasi interaktif yang tujuan utamanya adalah untuk menyediakan tidak hanya hiburan tetapi juga pelatihan di berbagai bidang seperti kesehatan, pemasaran, pendidikan, dan bidang lainnya. Sedangkan menurut Hssina, et al [] ], gim edukasi dapat memperkenalkan beberapa aktivitas melalui cara interaktif. Gim edukasi dapat menjadi alat bantuan untuk melengkapi metode pembelajaran tradisional sehingga dapat meningkatkan pengalaman pembelajaran serta meningkatkan kemampuan lain seperti: mengikuti peraturan, adaptasi, pemecahan masalah, interaksi, berpikir kritis, kreativitas, dan kemampuan tim [9]. Gim edukasi memiliki fitur seperti media edukasi lainnya namun dengan interaksi yang lebih banyak daripada media edukasi konvensional lain, sehingga sesuai untuk sarana sosialisasi dan edukasi.

\subsection{Gim Aksi}

Gim aksi pada umumnya menekankan pada tantangan refleks pemain, koordinasi tangan-mata, dan waktu reaksi. Pemain dapat berkembang dari suatu tingkat ke tingkat lain dengan tantangan gim perlahan naik dengan kecepatan tetap [10]. Gim aksi menawarkan sejumlah aksi yang intens sebagai daya tarik utamanya. Gim aksi memerlukan kemampuan respons reflek agar dapat dimainkan dengan baik [11].

\subsection{Sampah}

Dalam Pasal 1 Ayat 1 Undang - Undang No.18 tahun 2008 Tentang Pengelolaan Sampah, dikatakan bahwa sampah adalah sisa kegiatan sehari - hari manusia dan / atau proses alam yang berbentuk padat [1]. Dikutip dari Instruksi Gubernur No. 107 Tahun 2019, saat ini pemilahan sampah dibagi menjadi 7 jenis sampah yang meliputi [12]: sampah organik, sampah kertas, sampah elektronik, sampah bahan berbahaya \& beracun, sampah plastik, sampah logam, dan residu.

Dalam Pasal 15 Ayat 5 dalam Peraturan Menteri Pekerjaan Umum Republik Indonesia Nomor 03 Tahun 2013 Tentang Penyelenggaraan Prasarana dan Sarana Persampahan dalam Penanganan Sampah Rumah Tangga dan Sampah Sejenis Sampah Rumah Tangga, sampah yang dapat didaur ulang merupakan sampah yang dapat dimanfaatkan kembali setelah melalui proses pengolahan [13]. Dalam Pasal 1 Ayat 5 Undang - Undang No. 18 Tahun 2008, pengelolaan sampah merupakan kegiatan yang sistematis, menyeluruh, dan berkesinambungan yang meliputi pengurangan dan penanganan sampah [1]. 


\subsection{Elemen Gim}

Elemen formal adalah kumpulan elemen yang membantu dalam membangun struktur gim. Berikut elemen formal yang dapat digunakan dalam membentuk struktur gim [14], [15]:

1. Pemain: pengguna yang memainkan gim baik itu secara individu maupun kelompok.

2. Tujuan: hal yang dapat dicapai oleh pemain saat memainkan gim.

3. Prosedur: beberapa instruksi yang diikuti oleh pemain saat memainkan gim.

4. Aturan: konsep yang dibuat untuk mengatur apa yang dapat dilakukan dan tidak dapat dilakukan pemain saat memainkan gim.

5. Sumber daya: nilai-nilai yang dimiliki oleh pemain untuk mencapai tujuan individu mereka.

6. Konflik: hal yang dapat mencegah pemain untuk menyelesaikan sebuah tujuan berdasarkan aturan dan prosedur.

7. Batasan: hal yang terkait dengan tindakan yang hanya mungkin dalam gim.

8. Hasil: suatu hal yang bisa didapatkan oleh pemain setelah mencapai tujuan permainan. Hasil seringkali dapat diukur seperti poin atau skor, dan tidak merata seperti harus ada satu tim atau satu orang untuk menang.

\subsection{Game Development Life Cycle (GDLC)}

GDLC adalah suatu framework yang digunakan sebagai pedoman dalam pengembangan sebuah gim. Alur GDLC ditampilkan pada Gambar 1. Menurut Ramadan dan Widyani [14] yang dikutip oleh Dirgantara, et al [ㅁ] terdapat 6 tahapan dalam GDLC, yaitu:

1. Inisiasi: membuat game design dari gim yang akan dibuat.

2. Pra-produksi: membuat aset, mockup, dan struktur navigasi dari game design.

3. Produksi: membuat gim dari game design yang sebelumnya telah dirancang dalam pra-produksi.

4. Testing: pelaksanaan tes internal untuk mengecek fungsionalitas gim agar dapat dimainkan.

5. Beta: pelaksanaan tes eksternal agar mendapat umpan balik dari pihak eksternal (pemain).

6. Rilis: gim dapat dimainkan oleh masyarakat luas.

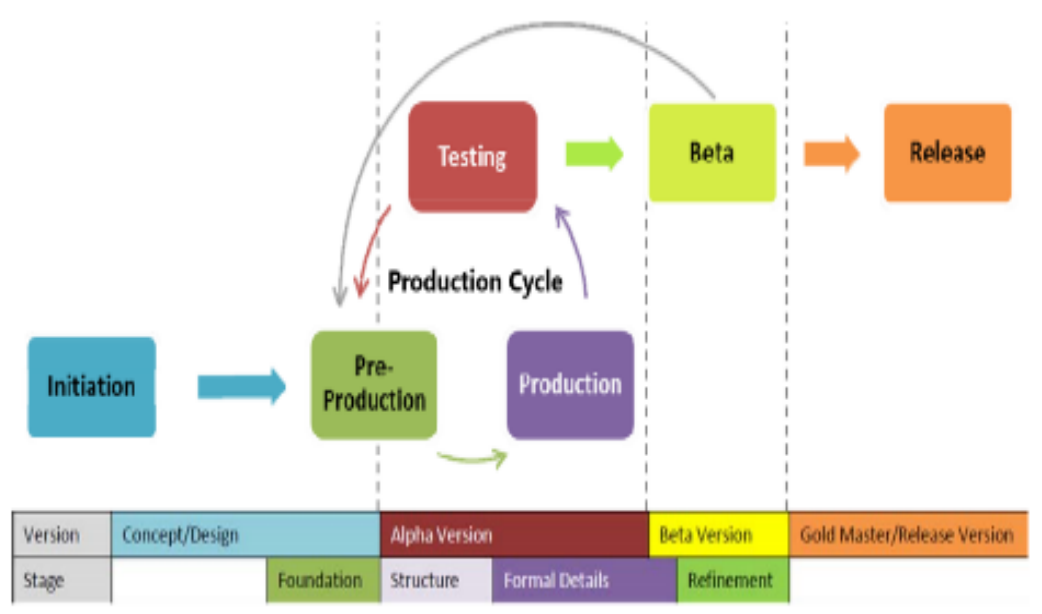

Gambar 1. Alur GDLC [16]

\subsection{Kerangka Pemikiran}

Kerangka pemikiran penelitian ini ditampilkan pada Gambar 2. Awal penelitian ini mendeskripsikan bahwa masih banyak sampah yang menumpuk yang sebenarnya dapat dipilah dan di daur ulang kembali sebagai tindakan nyata dalam menerapkan Pasal 12 Ayat 1 UU No. 18 tahun 2008. Dari data, referensi buku, jurnal, dan berita yang telah dikumpulkan akan dijadikan sebagai landasan dalam pembuatan gim dengan metode GDLC. Proses penelitian dimulai dari tahap inisiasi, membuat aturan bermain yang berlaku dalam gim dalam bentuk konsep-konsep yang tersusun. Tahap pre-produksi, membuat struktur navigasi, mockup dan aset dari konsep yang telah dibuat. Tahap produksi, dilakukan penggabungan dari semua aset dengan kode-kode dalam mesin gim Unity. Tahap testing menggunakan metode black box testing untuk menguji fungsi-fungsi yang sudah dibuat. 
Tahap beta dilaksanakan dengan melibatkan beberapa penguji secara acak untuk mendapatkan masukan atau umpan balik. Tahap rilis yang dapat diunduh dan dimainkan oleh masyarakat.

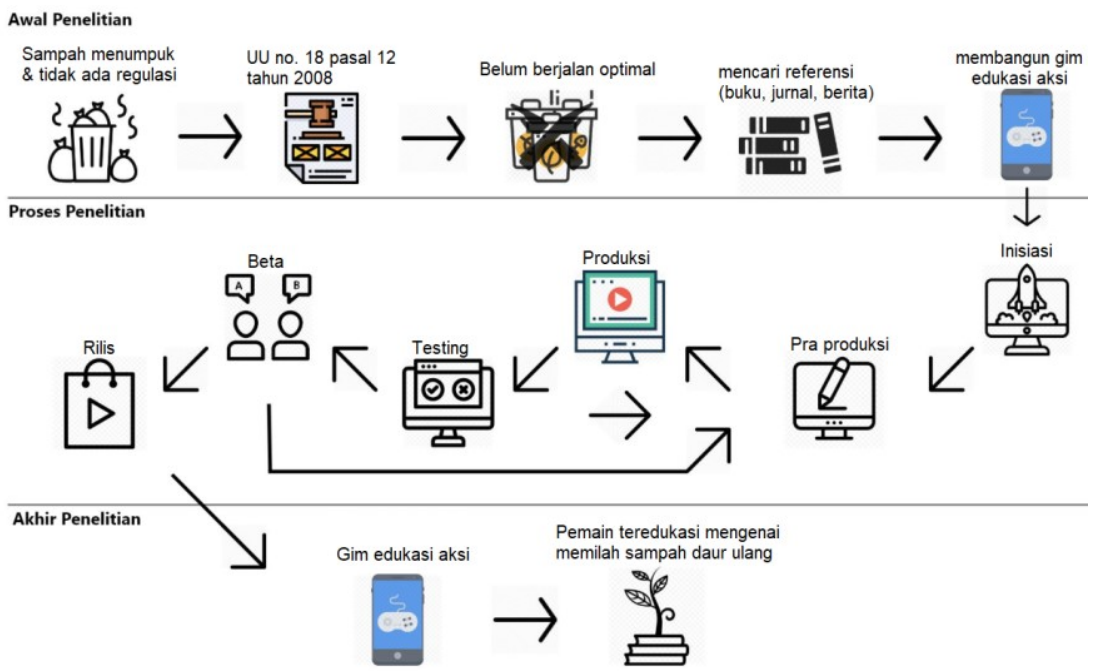

Gambar 2. Kerangka pemikiran

\section{HASIL DAN ANALISIS}

\subsection{Tahap Inisiasi}

Audiens gim ini adalah masyarakat umum, terutama pelaku sampah daur ulang. Konsep gim mengarahkan pemain (masyarakat umum) untuk mengenal dan mengetahui sampah daur ulang, residu, dan sampah organik, serta memperlihatkan hasil daur ulang yang dapat digunakan dengan format 2D. Dari hasil bermain gim ini, diharapkan pemain dapat tersosialisasi dan teredukasi terkait pemilahan sampah daur ulang. Terdapat 2 (dua) fitur utama yang terdapat dalam gim ini. Pertama adalah fitur bermain, pemain berperan sebagai Penyedia Jasa Layanan Perorangan (PJLP) yang ditempatkan di TPS dengan sistem pengangkutan kontainer tetap (Stationary Container System $=$ SCS). Konsep gim disajikan pada Tabel 1.

Tabel 1. Konsep Dasar Gim

\begin{tabular}{cc}
\hline Komponen & Keterangan \\
\hline Judul Gim & Kita Pilah Sampah Anda \\
Jenis Gim/Genre & Edukasi Aksi \\
Pengguna & Umum \\
\hline $\begin{array}{c}\text { Sudut Pandang Pemain } \\
\text { Gambar }\end{array}$ & Overhead \\
\hline
\end{tabular}

Pemain diharuskan untuk memilah sampah dengan benar dan cepat, dengan cara menggeser sampah ke area pemilahan yang dianggap benar oleh pemain selama waktu yang ditentukan, untuk menjaga daya tampung TPS agar tidak melebihi batas maksimum. Apabila benar dalam memilah sampah akan mendapat 50 poin. Tetapi apabila salah dalam memilah sampah akan berkurang 25 poin, hal tersebut akan berpengaruh terhadap skor akhir pemain.

Terdapat 2 tingkatan yang dapat dipilih oleh pemain. Perbedaan tingkat 1 dan tingkat 2 adalah terletak pada banyaknya jenis sampah yang masuk ke TPS dan jumlah jenis warna tempat sampah, semakin tinggi tingkatannya maka jenis sampah yang masuk ke TPS juga semakin banyak dan begitu pula jumlah jenis warna tempat sampah akan bertambah. Apabila daya tampung TPS melebihi batas maksimum, maka permainan berakhir dan skor akhir tidak di hitung. Terdapat fitur ensiklopedia yang berisikan nama dan jenis sampah yang akan dipilah pemain dalam fitur bermain, baik itu sampah daur ulan, residu, dan sampah organik. Dalam fitur ini juga disajikan contoh-contoh pemanfaatan sampah daur ulang dan organik.

Elemen formal ditentukan sebagai struktur dasar dalam proses pengembangan gim ini hingga selesai. Elemen formal pada gim "Kita Pilah Sampah Anda" disajikan pada Tabel 2. 
Tabel 2. Elemen Formal

\begin{tabular}{|c|c|}
\hline $\begin{array}{l}\text { Elemen } \\
\text { Formal }\end{array}$ & Deskripsi \\
\hline Pemain & Gim ini hanya dapat dimainkan secara Single Player. \\
\hline Tujuan & Pemain memilah sampah sebanyak-banyaknya dengan benar untuk mendapatkan skor tertinggi selama 1 menit. \\
\hline Prosedur & $\begin{array}{l}\text { Kontrol pemain dalam gim menggunakan gawai nya dengan cara menekan dan menggeser sampah ke area } \\
\text { pemilahan yang dianggap benar oleh pemain dalam waktu } 1 \text { menit. }\end{array}$ \\
\hline \multirow[t]{6}{*}{ Aturan } & 1. Latar Gim adalah Tempat Pembuangan Sementara (TPS). \\
\hline & 2. Pemain bermain dengan menggunakan layar sentuh gawai. \\
\hline & $\begin{array}{l}\text { 3. Pada saat bermain pemain akan memilih tingkat kesulitan dan selanjutnya sampah akan berdatangan ke } \\
\text { TPS, semakin tinggi tingkat kesulitan maka frekuensi sampah juga akan semakin banyak yang } \\
\text { berdatangan ke TPS. }\end{array}$ \\
\hline & $\begin{array}{l}\text { 4. Pada tingkat } 1 \text {, terdapat } 2 \text { area pemilahan (sampah daur ulang dan sampah organik). Sedangkan tingkat } 2 \\
\text { terdapat } 3 \text { area pemilahan (sampah daur ulang, sampah organik dan residu) }\end{array}$ \\
\hline & $\begin{array}{l}\text { 5. Pemain diharuskan memilah sampah dengan benar dengan cara meletakkan sampah yang dipilah pada } \\
\text { area pemilahan yang benar. Benar dapat } 50 \text { poin, salah }-25 \text { poin. }\end{array}$ \\
\hline & 6. Pemain dinyatakan kalah apabila daya tampung TPS melebihi batas maksimum. \\
\hline Sumber & 1. Skor Pemain \\
\hline \multirow[t]{2}{*}{ Daya } & 2. Waktu \\
\hline & Bar Daya Tampung TPS \\
\hline \multirow[t]{2}{*}{ Konflik } & Sampah yang terus berdatangan \\
\hline & 2. Pemain harus menjaga daya tampung TPS tidak melewati batas maksimum. \\
\hline \multirow[t]{3}{*}{ Batasan } & $\begin{array}{l}\text { 1. Terdapat } 2 \text { tingkat kesulitan pada gim ini. Perbedaan tingkat } 1 \text { dan tingkat } 2 \text { terletak pada jumlah } \\
\text { pengangkutan sampah ke TPS dan jumlah area pemilahan. Jumlah pengangkutan pada tingkat } 1 \text { lebih } \\
\text { rendah dari tingkat } 2 \text {. Tingkat } 1 \text { terdapat } 2 \text { warna area pemilahan sampah dan tingkat } 2 \text { terdapat } 3 \\
\text { warna area pemilahan sampah. }\end{array}$ \\
\hline & 2. Ada batasan waktu bagi pemain untuk memilah sampah daur ulang. \\
\hline & 3. Sampah hanya meliputi: sampah kertas, plastik, logam, residu, sampah organik \\
\hline Hasil & Hasil skor tertinggi yang diperoleh pemain akan tersimpan dan dimasukkan dalam papan peringkat. \\
\hline
\end{tabular}

\subsection{Tahap Pra-produksi}

Pembuatan aset menggunakan Paint.NET dengan gaya pixel art. Aset yang digunakan dalam pengembangan gim adalah macam-macam sampah daur ulang, residu, sampah organik, latar belakang berupa TPS, tombol, karakter, dan logo gim yang disajikan pada Tabel 4.

Tabel 4. Aset Gim

\begin{tabular}{|c|c|c|}
\hline Gambar & Keterangan & Referensi \\
\hline & Aset sampah logam (minuman kaleng) & Adjie Wahyudinata \\
\hline & Aset sampah plastik (botol plastik) & Adjie Wahyudinata \\
\hline & Aset sampah plastik (kantong kresek) & Adjie Wahyudinata \\
\hline & Aset sampah kertas & Adjie Wahyudinata \\
\hline & Aset sampah kertas (kardus) & Adjie Wahyudinata \\
\hline & Aset residu (popok bayi) & Adjie Wahyudinata \\
\hline & Aset residu (polystyrene) & Adjie Wahyudinata \\
\hline & Aset sampah organik (kulit pisang) & Adjie Wahyudinata \\
\hline & Aset sampah organik (sisa sayuran) & Adjie Wahyudinata \\
\hline & Aset karakter & Adjie Wahyudinata \\
\hline
\end{tabular}


Alur gim ini ditampilkan dengan struktur navigasi pada Gambar 3. Gim ini diawali dari menu (scene 1) yang selanjutnya terdapat empat pilihan menu, yaitu:

1. Bermain (scene 2). Pemain akan diarahkan ke tutorial (Scene 2.1) untuk membaca cara bermain. Kemudian pemain memasuki pilih tingkat kesulitan (Scene 2.2) untuk memilih tingkat kesulitan yang diinginkan. Setelah pemain memilih dan memasuki sesi permainan pada tingkat 1 (Scene 2.3) atau tingkat 2 (Scene 2.4), permainan dimulai hingga waktu yang ditentukan. Pemain dapat mengisi nama jika menang dan skor akan dihitung, yang nantinya akan disimpan dalam papan peringkat.

2. Ensiklopedia (scene 3). Ensiklopedia menampilkan apa saja jenis sampah yang terdapat dalam gim "Kita Pilah Sampah Anda".

3. Papan peringkat (scene 4). Papan peringkat menampilkan raihan skor yang telah diperoleh pemain saat selesai memasuki sesi permainan.

4. Kredit (scene 5). Kredit menampilkan aset eksternal apa saja yang digunakan dalam gim.

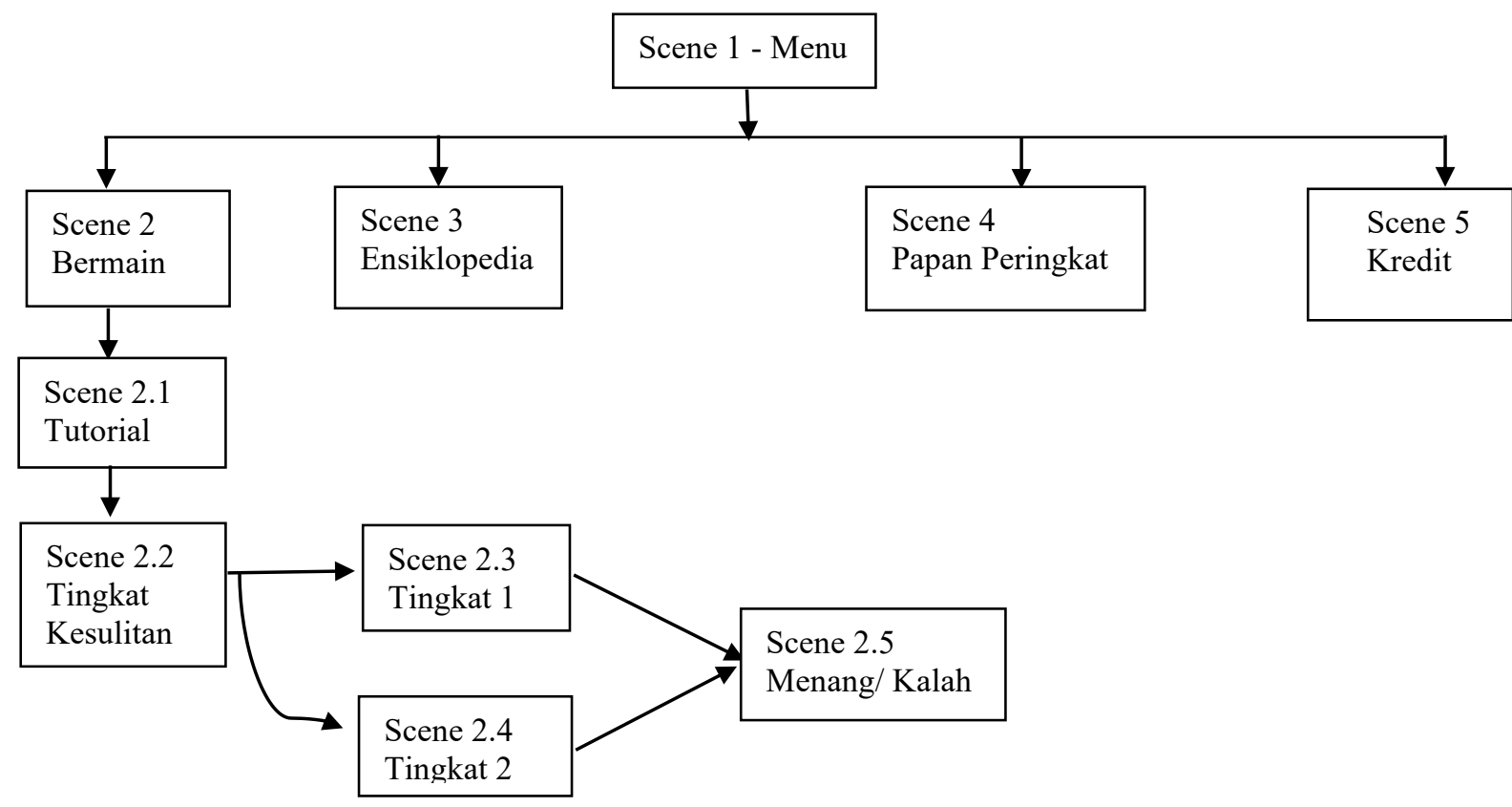

Gambar 3. Struktur navigasi

\subsection{Tahap Produksi}

Hasil pra-produksi yang sudah dirancang, kemudian diproduksi menjadi sebuah produk jadi berupa .apk yang nantinya dapat di uji oleh pengguna. Pembuatan gim dalam penelitian ini menggunakan mesin gim Unity. Hasil produksi gim yang telah dikembangkan, ditampilkan pada Gambar 4 sampai dengan Gambar 12. Gambar 4 menampilkan menu utama. Terdapat tombol bermain untuk menuju tampilan cara bermain, tombol ensiklopedia untuk masuk tampilan ensiklopedia, tombol papan peringkat untuk melihat tampilan papan peringkat, tombol kredit untuk mengakses tampilan kredit, dan tombol keluar untuk keluar dari gim.

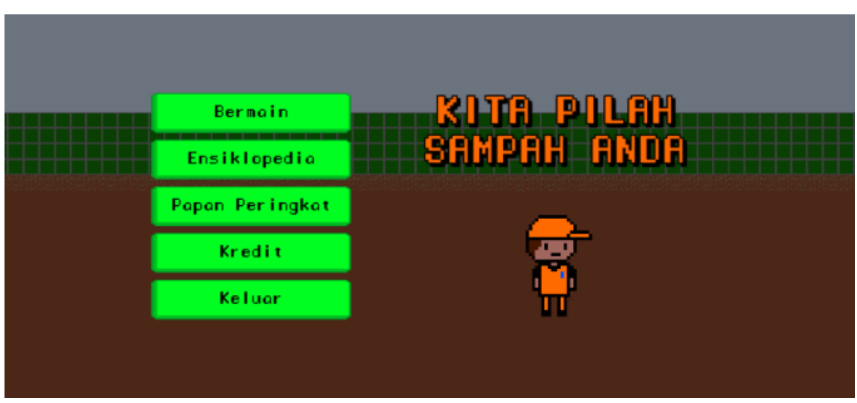

Gambar 4. Tampilan menu utama 
Gambar 5 menampilkan cara bermain. Terdapat instruksi cara bermain, mekanisme skor dalam permainan, dan kondisi menang dan kalah. Terdapat tombol selanjutnya menuju pilih tingkat kesulitan.

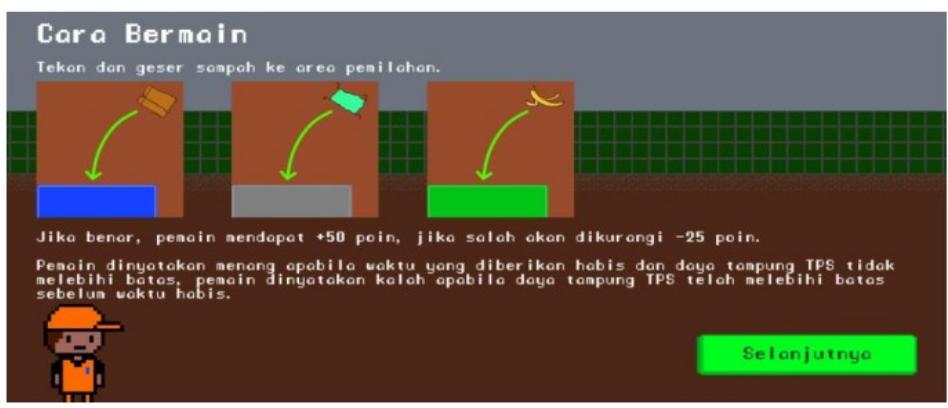

Gambar 5. Tampilan cara bermain

Gambar 6 menampilkan pilih tingkat kesulitan, terdapat 2 tombol yang tersedia yaitu tingkat 1 dan tingkat 2 yang mengarahkan pemain pada permainan yang sesuai dengan tingkat kesulitan yang dipilih. Pemain tidak dapat memainkan tingkat 2 apabila belum menyelesaikan tingkat 1, sehingga tampilan tombol tingkat 2 terlihat lebih gelap yang menandakan bahwa tombol tingkat 2 terkunci. Gambar 7 menampilkan pilih tingkat kesulitan dengan tombol tingkat 2 telah terbuka. Terlihat warna tombol tingkat 2 sudah memiliki warna yang sama dengan tombol tingkat 1 .

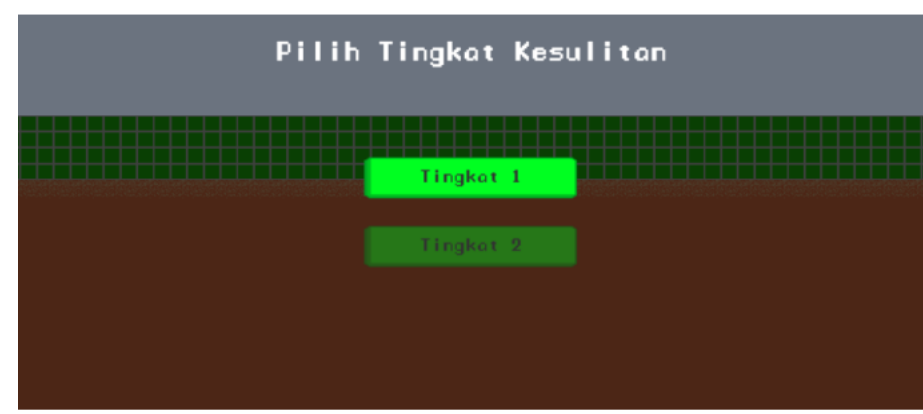

Gambar 6. Tampilan pilih tingkat kesulitan (belum menyelesaikan tingkat 1)

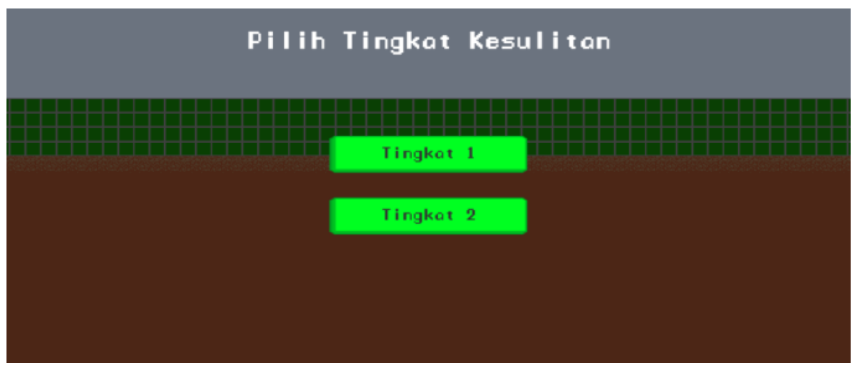

Gambar 7. Tampilan pilih tingkat kesulitan (sudah menyelesaikan tingkat 1)

Gambar 8 menampilkan in-game tingkat 1, terdapat skor sementara pemain, waktu yang tersisa, bar daya tampung TPS, area pemilahan sampah daur ulang dengan warna biru, dan area pemilahan sampah organik = dengan warna hijau. Pemain juga akan melihat 7 jenis sampah yang secara acak muncul pada tampilan ini. Gambar 9 menampilkan in-game tingkat 2, perbedaan antara in-game tingkat 1 dan tingkat 2 adalah adanya area pemilahan residu dengan warna abu-abu, dan terdapat 10 sampah yang secara acak muncul pada tampilan ini. 


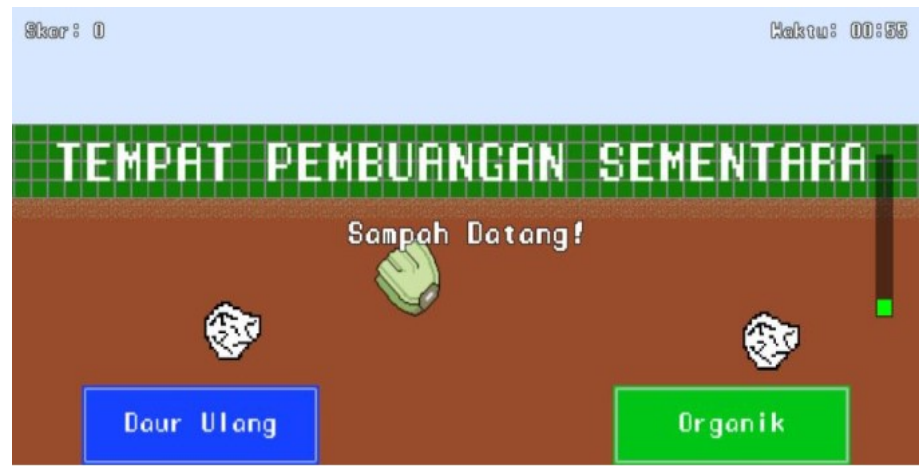

Gambar 8. Tampilan in-game tingkat 1

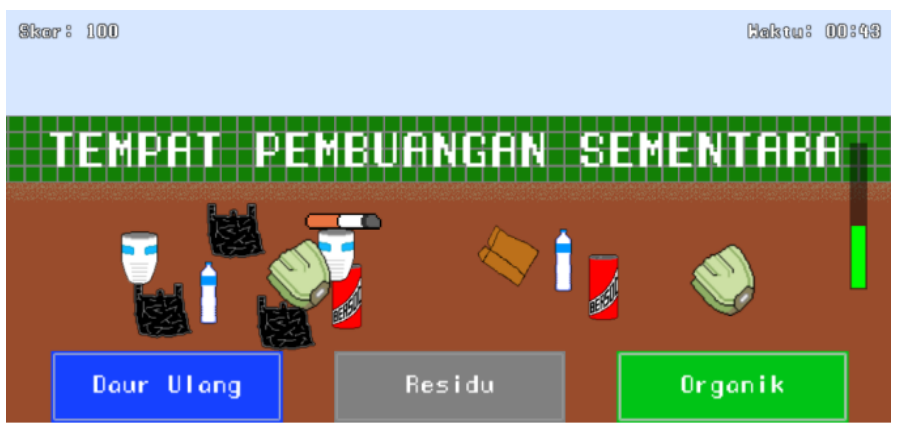

Gambar 9. Tampilan in-game tingkat 2

Tampilan permainan berakhir pada Gambar 10 baru muncul ketika pemain gagal menjaga daya tampung TPS tidak melewati batas maksimal. Terdapat tombol kembali untuk kembali ke menu utama. Tampilan pengisian nama pada Gambar 11 akan muncul apabila pemain berhasil menjaga bar daya tampung TPS tidak melebihi batas hingga waktu habis. Terdapat tampilan skor akhir pemain, Input field untuk mengisi nama, dan tombol selanjutnya yang mengarahkan pemain menuju tampilan papan peringkat.

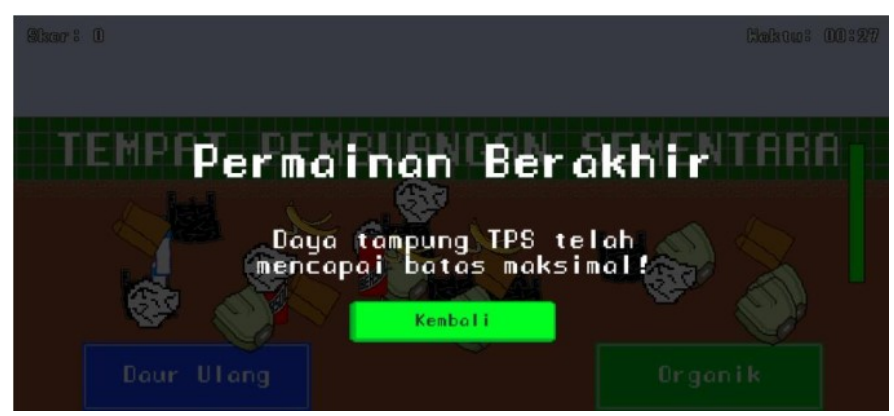

Gambar 10. Tampilan permainan berakhir

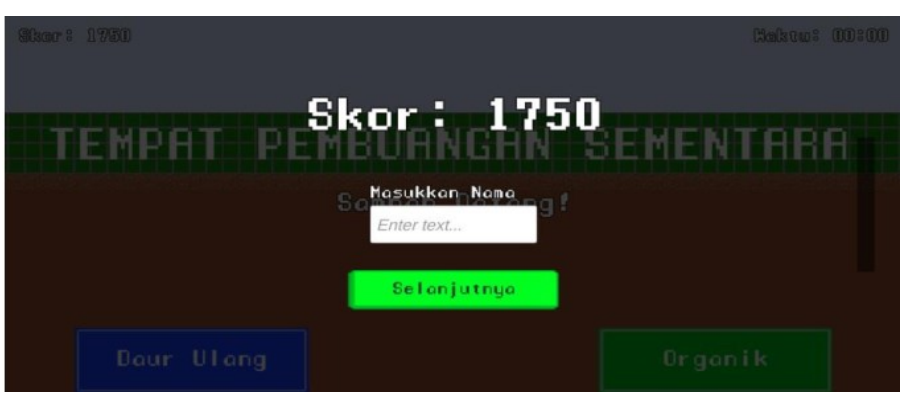

Gambar 11. Tampilan pengisian nama

Gambar 12 menampilkan ensiklopedia. Terdapat daftar sampah yang digunakan dalam gim ini, serta pemanfaatannya. Tombol " $<$ " dan " $>$ " digunakan untuk melihat halaman sebelumnya dan selanjutnya, kemudian tombol kembali untuk mengakses menu utama. 


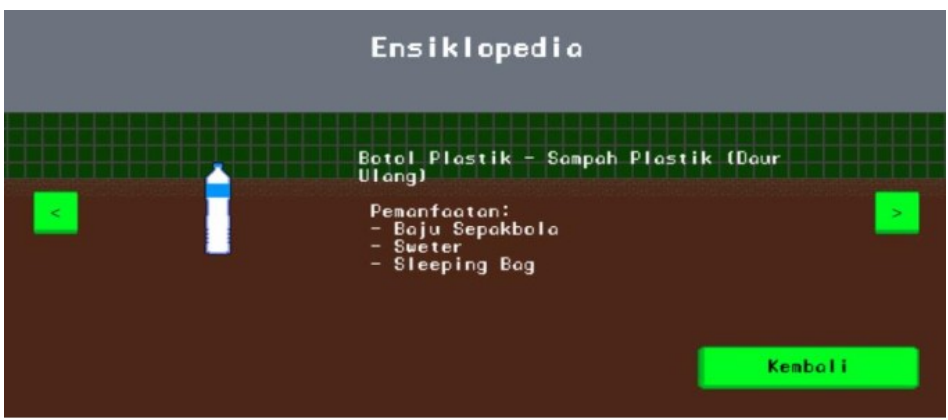

Gambar 12. Tampilan ensiklopedia

\subsection{Tahap Testing}

Pada tahap uji coba, dilakukan pengujian oleh tim peneliti dengan metode black box testing untuk memeriksa fungsi dalam gim sudah berjalan dengan benar. Setiap fungsi dalam gim harus diuji secara internal dulu sebelum dapat dirilis kepada masyarakat umum. Sehingga apabila terdapat error atau bug dapat segera diselesaikan. Hasil uji coba black box ditampilkan pada Tabel 5.

Tabel 5. Hasil Uji Coba Black Box

\begin{tabular}{cccc}
\hline No & Deskripsi Tes & Indikator Kesuksesan & Hasil \\
\hline 1 & Tombol bermain menu utama & Dapat mengakses cara bermain & Berhasil \\
2 & Tombol ensiklopedia menu utama & Dapat mengakses ensiklopedia & Berhasil \\
3 & Tombol papan peringkat menu utama & Dapat mengakses papan peringkat & Berhasil \\
4 & Tombol kredit menu utama & Dapat mengakses Kredit & Berhasil \\
5 & Tombol keluar menu utama & Sesi gim berakhir & Berhasil \\
6 & Tombol ganti halaman $(<$ dan $>$ ) scene Library & Menggeser halaman daftar sampah & Berhasil \\
7 & Tombol kembali scene Library & Mengakses kembali menu utama & Berhasil \\
8 & Tombol Tingkat 1 & Mengakses scene InGame_Levell & Berhasil \\
9 & Tombol Tingkat 2 (belum bermain tingkat 1) & Tidak dapat diakses & Berhasil \\
10 & Tombol Tingkat 2 (sudah bermain tingkat 1) & Mengakses scene InGame_Level2 & Berhasil \\
11 & Tombol selanjutnya scene tutorial & Mengakses tingkat kesulitan & Berhasil \\
12 & Menarik aset ke area pemilahan & Aset dapat ditarik oleh pemain & Berhasil \\
13 & Animasi aset hilang saat ditarik ke area pemilahan & Aset menghilang & Berhasil \\
14 & Benar memilah, skor bertambah & Skor pemain bertambah +50 & Berhasil \\
15 & Salah memilah, skor berkurang & Skor pemain berkurang -25 & Berhasil \\
16 & Saat pemain dinyatakan menang & Pemain diarahkan ke papan peringkat & Berhasil \\
17 & Saat kalah, menekan tombol kembali ke scene MainMenu & Pemain mengakses menu utama & Berhasil \\
18 & Mengisi nama dalam scene Leaderboard & Pemain men-submit nama ke papan peringkat & Berhasil \\
19 & Tombol kembali Leaderboard & Mengakses kembali menu utama & Berhasil \\
20 & Tombol kembali Credits & Mengakses kembali menu utama & Berhasil \\
\hline
\end{tabular}

\subsection{Tahap Beta}

Berdasarkan hasil pengujian tahap beta, sebanyak 21 responden masyarakat umum sebagai tester. Hasil jawaban tahap beta setelah bermain gim dapat dilihat pada Tabel 6 .

Tabel 6. Hasil Pengujian Beta Setelah Tester Bemain Gim

\begin{tabular}{|c|c|c|c|}
\hline \multirow{2}{*}{ No. } & \multirow{2}{*}{ Pertanyaan } & \multicolumn{2}{|c|}{ Jawaban } \\
\hline & & Ya & Tidak \\
\hline 1 & $\begin{array}{l}\text { Apakah User Interface dari gim ini mudah dimengerti (tampilan dan tombol yang ada } \\
\text { dalam permainan)? }\end{array}$ & $\begin{array}{l}95.2 \% \\
\text { responden }\end{array}$ & $4.8 \%$ responden \\
\hline 2 & Apakah objek dalam gim cukup jelas (aset gambar dalam permainan)? & $\begin{array}{l}90.5 \% \\
\text { responden }\end{array}$ & $9.5 \%$ responden \\
\hline 3 & Apakah pemilihan warna dalam gim ini nyaman untuk dilihat? & $\begin{array}{l}90.5 \% \\
\text { responden }\end{array}$ & $9.5 \%$ responden \\
\hline 4 & Apakah teks yang ada dalam gim cukup jelas? & $\begin{array}{l}95.2 \% \\
\text { responden }\end{array}$ & $4.8 \%$ responden \\
\hline 5 & $\begin{array}{l}\text { Setelah bermain, apakah pemain menjadi lebih paham mengenai pemilahan sampah daur } \\
\text { ulang? }\end{array}$ & $\begin{array}{l}95.2 \% \\
\text { responden }\end{array}$ & $4.8 \%$ responden \\
\hline 6 & $\begin{array}{l}\text { Setelah bermain, apakah pemain menjadi lebih paham mengenai jenis warna pewadahan } \\
\text { sampah? }\end{array}$ & $\begin{array}{l}85.7 \% \\
\text { responden }\end{array}$ & $14.3 \%$ responden \\
\hline 7 & Setelah bermain, apakah pemain tergerak untuk memilah sampah daur ulang sendiri? & $\begin{array}{l}76.2 \% \\
\text { responden }\end{array}$ & $23.8 \%$ responden \\
\hline
\end{tabular}




\subsection{Tahap Rilis}

Setelah seluruh tahapan pengembangan gim Kita Pilah Sampah Anda selesai, gim akan dirilis secara umum dalam format .apk yang dapat diunduh dalam situs web itch.io pada tautan berikut: https://dvlsh.itch.io/kitapilahsampahanda.

\section{KESIMPULAN}

Berdasarkan pengujian black box yang telah dilakukan, seluruh fungsionalitas pada gim "Kita Pilah Sampah Anda" berfungsi dengan baik. Sebanyak 76.2\% responden tergerak untuk memilah sampah daur ulang sendiri setelah menggunakan gim "Kita Pilah Sampah Anda". Sementara itu, sebanyak 95.2\% dari 21 responden menjadi lebih paham mengenai pemilahan sampah daur ulang setelah bermain gim ini.

\section{UCAPAN TERIMA KASIH}

Ucapan terima kasih penulis sampaikan kepada Ketua Program Studi Informatika yang sudah mendukung penyelesaian penelitan ini sehingga bisa diselesaikan tepat waktu.

\section{REFERENSI}

[1] Republik Indonesia, "Undang-Undang No 18 Tahun 2008 Tentang Pengelolaan Sampah.” Sekretariat Negara, Jakarta, 2008.

[2] Tim Publikasi Katadata, "Kesadaran Warga Memilah Sampah Masih Rendah,” 2020. [Online]. Available: https:/katadata.co.id/timpublikasikatadata/berita/5e9a470c74665/kesadaran-warga-memilahsampah-masih-rendah. [Accessed: 12-Jul-2020].

[3] E. Pujastuti, E. H. Saputra, and A. N. Rahmi, "Implementasi DGBL-ID Untuk Perancangan Game Edukasi 'Waste Management," Seminar Nasional Teknologi Informasi dan Multimedia 2018, vol. 6, no. $1,2018$.

[4] I. D. P. A. Sudiatmika, A. A. K. A. Cahyawan, and P. W. Buana, "Aplikasi Game Edukasi Trash Grabber untuk Mengenal Jenis-Jenis Sampah Pada Smartphone Berbasis Android," Jurnal Ilmiah Merpati (Menara Penelitian Akademika Teknologi Informasi), vol. 2, no. 2, pp. 215-225, 2014.

[5] R. Adiwikarta and H. B. Dirgantara, "Pengembangan Permainan Video Endless Running Berbasis Android Menggunakan Framework Game Development Life Cycle," Kalbiscientia : Jurnal Sains dan Teknologi, vol. 4, pp. 142-148, 2017.

[6] H. B. Dirgantara, Y. D. Prabowo, and M. M. Jermia, "Development of Android-Based Quiz Video Game: Mathventure," in International Joint Conference on Information, Media and Engineering, 2019, pp. $450-454$.

[7] P.-M. Noemí and S. H. Máximo, "Educational Games for Learning," Universal Journal of Educational Research, vol. 2, no. 3, pp. 230-238, 2014.

[8] B. Hssina, M. Erritali, B. Bouikhalene, and A. Merbouha, "Edugame an Android Game for Teaching Children," International Journal of Innovation and Applied Studies, vol. 9, no. 4, pp. 1531-1540, 2014.

[9] V. Zirawaga, A. Olusanya, and T. Maduki, "Gaming in Education: Using Games a Support Tool to Teach History," Journal of Education and Practice, vol. 8, no. 15, pp. 55-64, 2017.

[10] H. Gintis, Game Theory Evolving: a Problem-centered Introduction to Modeling Strategic Behavior. Princeton: Princeton University Press, 2000.

[11] M. Y. Abdullah, E. C. Djamal, and F. Renaldi, “Aksi Game Arcade Berdasarkan Pikiran Menggunakan Filter Fast Fourier Transform dan Learning Vector Quantization," in Seminar Nasional Aplikasi Teknologi Informasi, 2016.

[12] Provinsi DKI Jakarta, Instruksi Gubernur Daerah Khusus Ibukota Jakarta No 107 Tentang Pengurangan dan Pemilahan Sampah di Lingkungan Pemerintah Provinsi Daerah Khusus Ibu Kota Jakarta. 2019.

[13] Republik Indonesia, "Peraturan Menteri Pekerjaan Umum Nomor 03/PRT/M/2013 tentang Penyelenggaraan Prasarana dan Sarana Persampahan dalam Penanganan Sampah Rumah Tangga dan Sampah Sejenis Sampah Rumah Tangga.” Kementerian Pekerjaan Umum, Jakarta, pp. 1-374, 2013.

[14] R. Ramadan and Y. Widyani, "Game Development Life Cycle Guidelines," in International Conference on Advanced Computer Science and Information Systems, 2013, pp. 95-100.

[15] A. Alexiou and M. C. Schippers, "Digital Game Elements, User Experience and Learning: a Conceptual Framework," Education and Information Technologies, vol. 23, no. 6, pp. 2545-2567, 2018. 